\title{
SYNTHESES OF UNCONJUGATED $(Z, Z)$-DIOLEFINIC INSECT PHEROMONES ON INSOLUBLE POLYMER SUPPORTS
}

\author{
POLINA I. SVIRSKAYA and CLIFFORD C. LEZNOFF \\ Department of Chemistry, York University, \\ Downsview, Ontario, Canada M3J IP3
}

\begin{abstract}
A 2\% cross-linked styrene-divinylbenzene copolymer containing pendant trityl chloride groups was used as the solid support in the synthesis of $(Z, Z)-3,13$-octadecadien-1-yl acetate, a component of the sex attractant of the lesser peachtree borer, Synanthedon pictipes, the peachtree borer, Synanthedon exitiosa, and the cherry tree borer, Synanthedon hector. This solid-phase synthesis is compared with a similar synthetic approach in solution. The solid-phase synthesis of $(Z, Z)-7,11$-hexadecadien-I-yl acetate, a component of the pheromone of the pink bollworm moth, Pectinophora gossypiella is described.

Key Words- $(Z, Z)-3,13$-Octadecadien-1-yl acetate, $(Z, Z)-7,11$-hexadecadien-1-yl acetate, solid phase synthesis, Synanthedon pictipes, lesser peachtree borer, Synanthedon exitiosa, peachtree borer, Synanthedon hector, cherry tree borer, Pectinophora gossypiella, pink bollworm moth, Lepidoptera, Sessiidae, Gelechiidae.
\end{abstract}

\section{INTRODUCTION}

As stated by Henrick (1977): "The structures of many lepidopterous sex pheromones are deceptively simple but their efficient synthesis in high stereochemical purity has offered considerable synthetic challenge." A wide variety of syntheses of insect pheromones has been described (Henrick, 1977; Rossi, 1977). In our own laboratories we have synthesized a large number of stereochemically pure monoolefinic insect pheromones (Svirskaya et al., 1979; Fyles et al., 1977; Leznoff et al., 1977) on insoluble polymer supports (Leznoff, 1978; Fréchet, 1981). One advantage of using the 1 or $2 \%$ styrenedivinylbenzene copolymer supports containing trityl chloride groups (Fyles 
and Leznoff, 1976; Fréchet et al., 1976) was the selective monoblocking by the polymer of the symmetrical diol starting materials by the "fish hook" principle (Leznoff, 1978). Other advantages include a stereoselective Wittig reaction simulating "salt-free" conditions (Leznoff et al., 1977) and a facile borane addition reaction in which borane impurities are removed by simple filtration of the polymer (Fyles et al., 1977). Finally, the whole procedure of pheromone synthesis on solid phases has the potential to be automated, as shown for polypeptide (Erickson and Merrifield, 1976) and now oligonucleotide synthesis (Alvarado-Urbina et al., 1981).

We now report the preparation of some diolefinic insect pheromones on solid phases using symmetrical difunctional intermediates. Although the synthesis of $(Z, Z)-3,13$-octadecadien-1-yl acetate (1), a sex pheromone of the lesser peachtree borer, Synanthedon pictipes (Grote and Robinson), the peachtree borer, Synanthedon exitiosa (Say), and the cherry tree borer, Synanthedon hector (Butler), has been accomplished in solution (Doolittle et al., 1980; Uchida et al., 1978; Ebata and Mari, 1979) in several related ways, a retrosynthetic analysis of 1 reveals the presence of a symmetrical difunctional $-\left(\mathrm{CH}_{2}\right)_{8}$ - unit in the middle of 1 and, since solid-phase methodology lends itself to the use of symmetrical difunctional intermediates, the advantageous use of polymer supports in the preparation of $\mathbf{1}$ is indicated.

\section{METHODS AND MATERIALS}

All melting and boiling points are uncorrected. Infrared spectra (IR) were recorded on a Unicam SP1000 IR spectrophotometer as neat films between $\mathrm{NaCl}$ disks or $\mathrm{KBr}$ plates. Nuclear magnetic resonance spectra (NMR) were recorded on a Varian EM360 spectrometer, with deuteriochloroform as solvent and tetramethylsilane as an internal standard. Mass spectra (MS) were recorded at $70 \mathrm{eV}$ on a VG Micromass $16 \mathrm{~F}$ mass spectrometer in the EI mode.

High-pressure liquid chromatographs were run with a Waters Associates model 440 instrument, with an $\mathrm{R}-400$ refractive index detector and a $30 \times 0.4$ $\mathrm{cm}$ reverse-phase $\mu$ Bondapak C-18 column using water-acetonitrile ( $1: 3)$ for the $\mathrm{C}_{16}-\mathrm{C}_{18}$ diyne acetates, and a Zorbax ODS column $(25 \mathrm{~cm} \times 0.9 \mathrm{~mm})$ using water-acetonitrile $(1: 9)$ for the $\mathrm{C}_{16}$ diene-acetate and acetonitrile eluant for the $\mathrm{C}_{18}$ diene acetate, at a flow rate of $1.0-1.5 \mathrm{ml} / \mathrm{min}$. Experiments involving reactive organometallic reagents or boron hydrides extremely sensitive to air and moisture were carried out under an argon atmosphere, using dry and pure solvents.

Tetrahydrofuran (THF) was refluxed over $\mathrm{LiAlH}_{4}$ for $4 \mathrm{hr}$ and distilled under argon. Freshly distilled THF was always used. Hexamethylphosphoric 
triamide (HMPT) (Caution: hazardous) and other solvents were dried and distilled according to standard methods.

Silica gel was used for all thin and preparative layer chromatography (TLC) unless otherwise specified. Preparative TLC fractions were extracted with ether in a Soxhlet extractor. Filtration was done under vacuum through sintered glass Buchner funnels. The phrase "polymer was washed below" refers to the following procedure: after a polymer-bound compound was filtered; it was washed at least two times with the same solvent in which the reaction was carried out. The polymer was washed 2-3 times with THF, ethanol, 3-5 times with water, and 2-3 times with ethanol. The polymer was then washed 2-3 times with the solvent in which the reaction was carried out and finally 2-3 times with ethanol and 3-4 times with ether. The polymers, after being washed and air-dried, were transferred to a thimble in a Soxhlet extractor in which molecular sieves $(3 \AA)$ had been placed in a second thimble, and the polymer was extracted with dry benzene (or ether) for 3-5 hr under reflux conditions. The polymer was washed with dry ether and dried in vacuo. The reaction schemes are shown in Figures 1 to 4 .

Polymer-BoundDiol (3). The slurry of $15 \mathrm{~g}$ of 2 , containing $1.3 \mathrm{mmol}$ $\mathrm{Cl} / \mathrm{g}$ and $15 \mathrm{~g}$ of 1,2 -ethanediol in $5 \mathrm{ml}$ pyridine was heated at $70-80^{\circ}$ (bath) under argon overnight. Polymer 3 was isolated as previously described (Fyles and Leznoff, 1976). Cleavage with acetyl chloride in glacial acetic acid gave 1 $\mathrm{mmol} / \mathrm{g}$ of 1,2-ethanediyl diacetate.

Polymer-Bound Monomesylate (4). Into a three-necked flask fitted with a magnetic stirrer, a dropping funnel, a thermometer, and a $\mathrm{CaCl}_{2}$ drying tube was placed $15 \mathrm{~g}$ of vacuum-dried polymer $3,150 \mathrm{ml}$ of dry methylene chloride, and $20 \mathrm{~g}$ of dry triethylamine. To this suspension at -10 to $0^{\circ}$ was added slowly $10 \mathrm{~g}$ of freshly distilled methanesulfonyl chloride. The reaction mixture was stirred at $0^{\circ}$ for $12-16 \mathrm{hr}$, and the resin 4 was filtered, washed, extracted with benzene in a Soxhlet extractor, and vacuum dried. The slightly yellow polymer (4) formed showed very strong absorptions at 1170 and $1360 \mathrm{~cm}^{-1}$ in its IR spectrum. Standard acid cleavage of $1.0 \mathrm{~g}$ of 4 with $0.35 \mathrm{M} \mathrm{HCl}$ in dioxane (Fyles, 1976) after preparative TLC gave $0.61 \mathrm{mmol} / \mathrm{g}$ of 5 .

Polymer-Bound 3-Butyn-1-ol (6). A slurry of $3 \mathrm{~g}$ of the $\mathrm{LiC} \equiv \mathrm{CH} \cdot \mathrm{EDA}$ complex and $10 \mathrm{~g}$ of 4 in $75 \mathrm{ml}$ of a $2: 1$ mixture of THF and HMPT under argon was heated at $60^{\circ}$ (bath) overnight. The reaction mixture was cooled, and the excess of lithium acetylide was quenched with $\mathrm{THF}-\mathrm{H}_{2} \mathrm{O}(1: 1)$. The resin (6) was filtered, washed, extracted with ether in a Soxhlet extractor, and dried in vacuo.

Polymer-bound 3-butyn-1-ol (6) was also prepared from $5 \mathrm{~g}$ of 2 and $5 \mathrm{~g}$ of 7 in pyridine according to the procedure described above for 3.

Polymer-Bound 12-Bromo-3-dodecyn-1-ol (9). Into $100 \mathrm{ml}$ of THF in a $250-\mathrm{ml}$ three-necked flask, was placed $8 \mathrm{~g}$ of polymer 6. The flask was 
equipped with a magnetic stirrer, thermometer, argon-air inlet, condenser (without water) connected with a large needle directly to the atmosphere, and kept at $60^{\circ}$ (oil bath). To the stirred slurry was added, over a 15-min period, 10 $\mathrm{ml}$ of $t$-BuLi (2 $\mathrm{M}$ in pentane).

The reaction is very exothermic. The pentane was evaporated after the addition of $t$-BuLi was complete, water was passed through the condenser, and the resulting blood-red mixture was stirred for a further $0.75 \mathrm{hr}$ at $60^{\circ}$. The reaction mixture was cooled to room temperature, and $13.5 \mathrm{~g}$ of 1,8 dibromooctane (8) in $40 \mathrm{ml}$ of HMPT was added (at once). The reaction mixture was stirred overnight, treated with $\mathrm{THF}-\mathrm{H}_{2} \mathrm{O}$, and filtered. The excess of 8 was recovered from the filtrate $(10 \mathrm{~g})$. The polymer $(9)$ was washed, extracted with benzene in a Soxhlet extractor, and dried. Acid cleavage of 1.0 $\mathrm{g}$ of 9 and purification by preparative TLC on silica gel (eluant ether- $\mathrm{C}_{6} \mathrm{H}_{6}$ 1:4) gave $87 \mathrm{mg}(0.33 \mathrm{mmol} / \mathrm{g})$ of 10 . IR (neat) $\nu \mathrm{cm}^{-1}: 3350(\mathrm{OH})$ and 1040 (C-O). NMR: $\delta 3.8-3.2(4 \mathrm{H}, \mathrm{m}$, overlapping triplets); $2.62-1.10(17 \mathrm{H}$, broad); 1.4 (s). (Found: C 55.29; $\mathrm{H}$ 8.39. Calc. for $\mathrm{C}_{12} \mathrm{H}_{21} \mathrm{BrO}$ : $\mathrm{C} 55.17 ; \mathrm{H} \mathrm{8.10.)} \mathrm{A}$ similar experiment was carried out using 6, prepared directly from commercial 7. Acid cleavage gave $0.34 \mathrm{mmol} / \mathrm{g}$ of 10.

Polymer-Bound 3,13-Octadecadiyn-1-ol(12). To a stirred solution of 4.1 $\mathrm{g}(50 \mathrm{mmol})$ of 1 -hexyne in $20 \mathrm{ml}$ of THF at -10 to $0^{\circ}$ was added dropwise 35 $\mathrm{ml}(51 \mathrm{mmol})$ of $n$-BuLi in hexane under argon. The reaction mixture was stirred at $0^{\circ}$ for $1 \mathrm{hr}$, and a slurry of 1-lithiohexyne (11) was added by syringe to the suspension of $7.5 \mathrm{~g}$ of 9 , containing $2.4 \mathrm{mmol}$ of 10 in $50 \mathrm{ml}$ of HMPT. The stirring was continued overnight, the reaction mixture was cooled and hydrolyzed with $\mathrm{THF}-\mathrm{H}_{2} \mathrm{O}$. The product 12 was isolated by filtration, washed, and dried. Acid cleavage of $1 \mathrm{~g}$ of 12 and purification of the diynol 13 by preparative TLC on silica gel (eluant ether $\left.-\mathrm{C}_{6} \mathrm{H}_{6}, 1: 4\right)$ gave $72 \mathrm{mg}(0.27$ $\mathrm{mmol} / \mathrm{g}$ ) of pure $13, \mathrm{mp} 27-28^{\circ}$. The IR and NMR spectra were identical with the published spectra (Doolittle et al., 1980; Uchida et al., 1978; Ebata and Mori, 1979). Analysis of the acetate by $\mathrm{HPLC}$ (mobile phase $\mathrm{H}_{2} \mathrm{O}-\mathrm{CH}_{3} \mathrm{CN}$, $1: 3)$ showed one single peak of chemical purity greater than $99 \%$.

Polymer-Bound Dienol (14). To a $10-\mathrm{mmol}$ solution of (Sia) $)_{2} \mathrm{BH}$ or slurry of dicyclohexylborane in THF, prepared as described previously (Svirskaya et al., 1980), was added at $0-2^{\circ} \mathrm{C} 2-3 \mathrm{~g}$ of 12 containing $0.5-0.7$ $\mathrm{mmol}$ of 13 under argon. The reaction mixture was stirred at $0-2^{\circ}$ (cold plate) for $24 \mathrm{hr}$. To the cool suspension, $2 \mathrm{ml}$ of $\mathrm{AcOH}$ was added dropwise. The cold plate was removed. The mixture was allowed to warm to room temperature and was stirred for an additional $0.5 \mathrm{hr}$. The polymer was filtered, washed, and dried.

(Z,Z)-3,13-Octadecadien-1-ol(15). Acid cleavage of 14 and purification by column chromatography gave product of $>99 \%$ purity. The IR and NMR spectra of 15 were similar to those of an authentic sample.

(Z,Z)-3,13-Octadecadien-1-yl Acetate (1). Acetylation of 15, as described 
in the literature (Uchida eta 1., 1978) gave acetate 1, which was analyzed by HPLC. The $\mu$ Bondapak $\mathrm{C}_{18}$ column did not completely separate isomers ( $>99 \%$ purity), but isomers can be separated using a Zorbax ODS (Dupont) column. The analysis indicated ratios of $Z, Z$ to $(Z, E$ and $E, Z$ ) as $93: 7$ (on the polymer) and 95-96:5-4 in solution.

9-Tetradecyn-1-ol (22). Compound 21 was prepared from 8-chlorooctan1-yl tetrahydropyranyl ether (20) $(7.44 \mathrm{~g}, 30 \mathrm{mmol})$ and 1-lithiohexyne (11) (which was formed from $2.87 \mathrm{~g}, 35 \mathrm{mmol}$ of hexyne and $23 \mathrm{ml}, 33 \mathrm{mmol}$ of $n$-BuLi) in a solution of THF-HMPT by the method of Schwartz and Waters (1972). The crude $21(10 \mathrm{~g})$ was treated with a methanolic solution of $\mathrm{m}$ benzenedisulfonic acid to remove the THP-protecting group. The pure alcohol 22 was obtained after column chromatography on silica gel (eluant, ether-benzene, $15: 85)$ and distillation in $84 \%$ yield $(5.3 \mathrm{~g})$, bp $118-120^{\circ} / 0.35$ $\mathrm{mm}, n_{\mathrm{D}}^{20} 1.4630$ [lit. (Uchida eta $1 ., 1978$ ) bp $122-126 / 0.65 \mathrm{~mm}, n_{\mathrm{D}}^{22} 1.462 \mathrm{l}$ ].

1-Bromo-9-tetradecyne (23). The bromination of $22(5.2 \mathrm{~g}, 24 \mathrm{mmol})$ with bromine $(4.8 \mathrm{~g}, 30 \mathrm{mmol})$, triphenylphosphine $(7.5 \mathrm{~g}, 30 \mathrm{mmol})$, and pyridine $(5 \mathrm{ml})$ in dioxane $(100 \mathrm{ml})$, as described by Disselnkotter et al. (1976), gave the crude product 23 in quantitative yield. Column purification on silica gel (eluant, hexane-benzene $1: 1$ ) and further distillation afforded pure product $23(5.4 \mathrm{~g})$ in $84 \%$ yield, bp $126-128^{\circ} / 0.1 \mathrm{~mm}$. NMR $\delta: 3.6(\mathrm{t}, 2 \mathrm{H}, J=7 \mathrm{~Hz}), 2.0$ $(\mathrm{m}, 4 \mathrm{H}), 1.8-1.2(\mathrm{~m}, 16 \mathrm{H}) 0.9(\mathrm{t}, 3 \mathrm{H}, J=7 \mathrm{~Hz})$.

3,13-Octadecadiyn-l-ol (13). To a stirred solution of the lithium salt of the tetrahydropyranyl ether of 3-butyn-1-ol (16), prepared from $3.1 \mathrm{~g}, 20$ mmol of the tetrahydropyranyl ether of 3-butyn-1-ol in $20 \mathrm{ml} \mathrm{THF}$, and 20 mmol $n$-BuLi in hexane at -10 to $0^{\circ}$ (the mixture was kept $1 \mathrm{hr}$ at $0^{\circ}$ ), was added dropwise $4.4 \mathrm{~g}$ (16 mmol) of 1-bromo-9-tetradecyne (23) in $20 \mathrm{ml}$ HMPT. The deep blue solution was stirred for $0.5 \mathrm{hr}$ at $0^{\circ}, 2 \mathrm{hr}$ at room temperature, and $1 \mathrm{hr}$ at $40^{\circ}$. The mixture was poured into ice-water, the resulting colorless solution was separated, and the aqueous layer was thoroughly extracted with hexane. The combined organic extracts were washed with water and dried over $\mathrm{K}_{2} \mathrm{CO}_{3}$. Removal of the solvent gave $5 \mathrm{~g}$ $(90 \%)$ of crude tetrahydropyranyl ether of 13 . The hydrolysis of the protecting group was effected by warming the crude product with $m$-benzenedisulfonic acid in aqueous methanol at $50^{\circ}$ for $2 \mathrm{hr}$ and at room temperature overnight to give the free alcohol 13.

Diyne 13 was worked up in the usual manner and purified by column chromatography on alumina (Woelm, neutral, grade II, eluant etherbenzene, 15:85). The pure fraction $(3.5 \mathrm{~g}, 85 \%)$ was distilled (Kugelrohr, bath

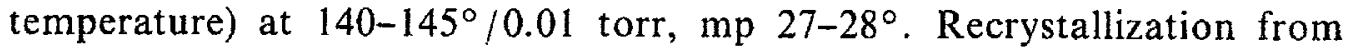
hexane gave $13 \mathrm{mp} 29-30^{\circ}$. Analysis of the acetate of 13 on the HPLC showed that the product was $>99 \%$ pure [lit. (Doolittle et al., 1980; Uchida et al.,

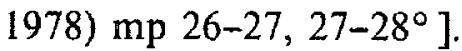

Borane Reduction of Diynol 13 to 15 in Solution. The diynol 13 was 
reduced with dicyclohexylborane in THF at -5 to $0^{\circ}$ for $4 \mathrm{hr}$ and for an additional $2 \mathrm{hr}$ at room temperature, or with disiamylborane for $24 \mathrm{hr}$ at $0^{\circ}$. (Reduction of the diynol 13 with (Sia) ${ }_{2} \mathrm{BH}$ for $6 \mathrm{hr}$ gave a mixture of mono and bis reduction product.)

Products were hydrolyzed with glacial acetic acid at $40-50^{\circ}$ for $5 \mathrm{hr}$ and oxidized with $30 \% \mathrm{H}_{2} \mathrm{O}_{2}$ in $6 \mathrm{~N} \mathrm{NaOH}$. The dienol was worked up and purified by column chromatography on alumina (grade 2) to give the $Z, Z$ isomer in $80-85 \%$ yield of $>99 \%$ purity. HPLC analysis of the acetate (Zorbax ODS column) gave $95-93 \%$ of the $Z, Z$ isomer.

Polymer-Bound Diol (27). A slurry of $20 \mathrm{~g}$ of 2 and $18 \mathrm{~g}$ of $26 \mathrm{in} 125 \mathrm{ml}$ of pyridine was stirred at room temperature for $48 \mathrm{hr}$ to give polymer 27 . Cleavage of 27 with $0.3 \mathrm{~N} \mathrm{HCl}$ in dioxane, as previously described (Fyles and Leznoff, 1976), gave $1.1 \mathrm{mmol}$ of $26 / \mathrm{g}$ of 27.

Polymer-Bound Monomesylate (28). Compound 28 was prepared according to the procedure described for 4 above. Cleavage of 28 as before yielded $0.62 \mathrm{mmol}$ of 1,6-hexanediol monomesylate (29)/g of 28 .

Polymer-Bound 7-Octyn-1-ol (30). Compound 30 was prepared according to the procedure described for 6 above. Acid cleavage of 30 gave 0.31 mmol of 7-octyn-1-ol (31)/g of $\mathbf{3 0}$.

Reaction of Polymer-Bound 7-Octyn-1-ol (30) with t-BuLi and 3-Octyn1-yl Mesylate (32). Cleavage of polymer, which formed in the usual coupling reaction described for 9 , from polymer 30, $t$-BuLi and 3-octyn-1-ol mesylate (32) gave only $0.30 \mathrm{mmol} / \mathrm{g}$ of the starting alcohol 7-octyn-1-ol (31).

Reaction of Lithium Salt of Tetrahydropyranyl Ether of 7-Octyn-1-ol with 1-Bromo-3-octyne (32a). Conditions of the coupling reaction were analogous to those for compound 13. After the organic layer was separated, washed, dried; the solvent was distilled (short path); and the residue was chromatographed on silica gel. The first component isolated from the column (eluant pentane) as a colorless oil was 1-octen-3-yne (33). The physical and spectroscopic data were identical with those described by Anzilotti (1939). The compound eluted with benzene was the starting tetrahydropyranyl ether of 7-octyn-1-ol.

Polymer-Bound 7,11-Dodecadiyn-1-ol (35). The coupling reaction was carried out as for 12, but the reaction mixture was stirred for $1 \mathrm{hr}$ at room temperature and $1 \mathrm{hr}$ at $40^{\circ}$. The product after cleavage was isolated by preparative TLC (solvent ether-benzene, $3: 7)$ to give $30 \mathrm{mg}(0.17 \mathrm{mmol} / \mathrm{g}$ ) of 7,11-dodecadiyn-1-ol (36).

Polymer-Bound 7,11-Hexadecadiyn-I-ol (37). Polymer 37 was prepared in a typical procedure described above from the lithium salt of polymer-bound 7,11-dodecadiyn-1-ol and butyl bromide and in a sepalrate experiment from polymer-bound 1,6-hexanediol monomesylate (28) and I-lithio-1,5-decadiyne (38). After cleavage and purification using flash chromatography (Still, 
$1978), 30 \mathrm{mg}(0.12 \mathrm{mmol} / \mathrm{g})$ of 7,11 -hexadecadiyn-1-ol (39) was isolated in the first experiment, and $50 \mathrm{mg}(0.21 \mathrm{mmol} / \mathrm{g})$ of 39 in the second.

Polymer-Bound (Z,Z)-7,11-Hexadecadien-1-ol (40). Reduction of the polymer $\mathbf{3 7}$ as for $\mathbf{1 2}$ gave $\mathbf{4 0 .}$

$(Z, Z)-7,11$-Hexadecadien-1-ol (41). Acid cleavage of $1 \mathrm{~g}$ of 40 gave $39 \mathrm{mg}$ or $0.16 \mathrm{mmol} / \mathrm{g}$ of $(Z, Z)-7,1$-hexadecadien-I-ol (41). HPLC analysis of the acetate, prepared as before, using the $\mu$ Bondapak $C_{18}$ column showed only a single peak ( $>99 \%$ purity), but isomers were separated on a Zorbax ODS column. Analysis by HPLC showed that reduction of diynols 37 and 39 with dicyclohexylborane gave dienols of higher stereochemical purity (93-96\%) than reduction with disiamylborane (90\%).

\section{RESULTS AND DISCUSSION}

The solution-phase synthesis of 1 by Doolittle et al. (1980) used 1-chloro8-iodooctane prepared in $41 \%$ yield from the symmetrical 1,8-dichlorooctane, while an alternate synthesis by Uchida et al. (1979) used the tetrahydropyranyl ether of 8-chlorooctan-1-ol, itself prepared from the symmetrical 1,8octanediol. Polymer-bound trityl chloride (2) reacted with excess 1,2ethanediol to give the monoreacted polymer-bound monotrityl ether of 1,2ethanediol (3) by methods previously described (Fyles and Leznoff, 1976). Subsequent reaction of 3 with methanesulfonyl chloride $(\mathrm{MsCl})$ in methylene chloride and triethylamine (Svirskaya et al., 1979) yielded the polymer-bound monotrityl ether of 1,2-ethanediol monomesylate (4). This modified mesylation procedure affords the monomesylate 4 in high yield as acid cleavage (Svirskaya et al., 1979; Leznoff et al., 1977) of 4 liberates $0.61 \mathrm{mmol}$ of 1,2-ethanediol monomesylate (5) per $\mathrm{g}$ of polymer 4 . Coupling of 4 with the lithium acetylide-ethylenediamine ( $\mathrm{LiC} \equiv \mathrm{CH} \cdot \mathrm{EDA})$ complex in $2: 1$ tetrahydrofuran (THF)-hexamethylphosphoric triamide (HMPT) yielded the polymer-bound trityl ether of 3-butyn-1-ol (6). Alternatively, 2 reacted directly with commercially available 3-butyn-1-ol (7) to give 6 in one step, but from the more expensive precursor 7. Treatment of 6 with $n$-BuLi and a large excess of the symmetrical 1,8-dibromooctane (8) led to the polymer-bound bromoalkyne (9). Acid cleavage of 9 gave 12-bromo-3-dodecyn-1-ol (10) in $54 \%$ yield based on 4 and showed that 9 contained at least $0.33 \mathrm{mmol}$ of $10 \mathrm{per}$ gram of polymer 9. Coupling of 9 with 1-lithiohexyne (11) in THF-HMPT gave the polymer-bound diyne (12). Acid cleavage of 12 gave 3,13-octadecadiyn-1-ol (13) in $82 \%$ yield based on polymer 9 . Reduction of 12 with dicyclohexylborane (Zweifel and Polston, 1970) or disiamylborane (Brown and Zweifel, 1961) yielded the polymer-bound cis, cis-diene 14. Acid cleavage of 14 gave $(Z, Z)-3,13$-octadecadien-1-ol (15) in $67 \%$ yield based on polymer 12. Acetylation of $\mathbf{1 5}$ gave $\mathbf{1}$ (Figure 1) in nearly quantitative yield. 


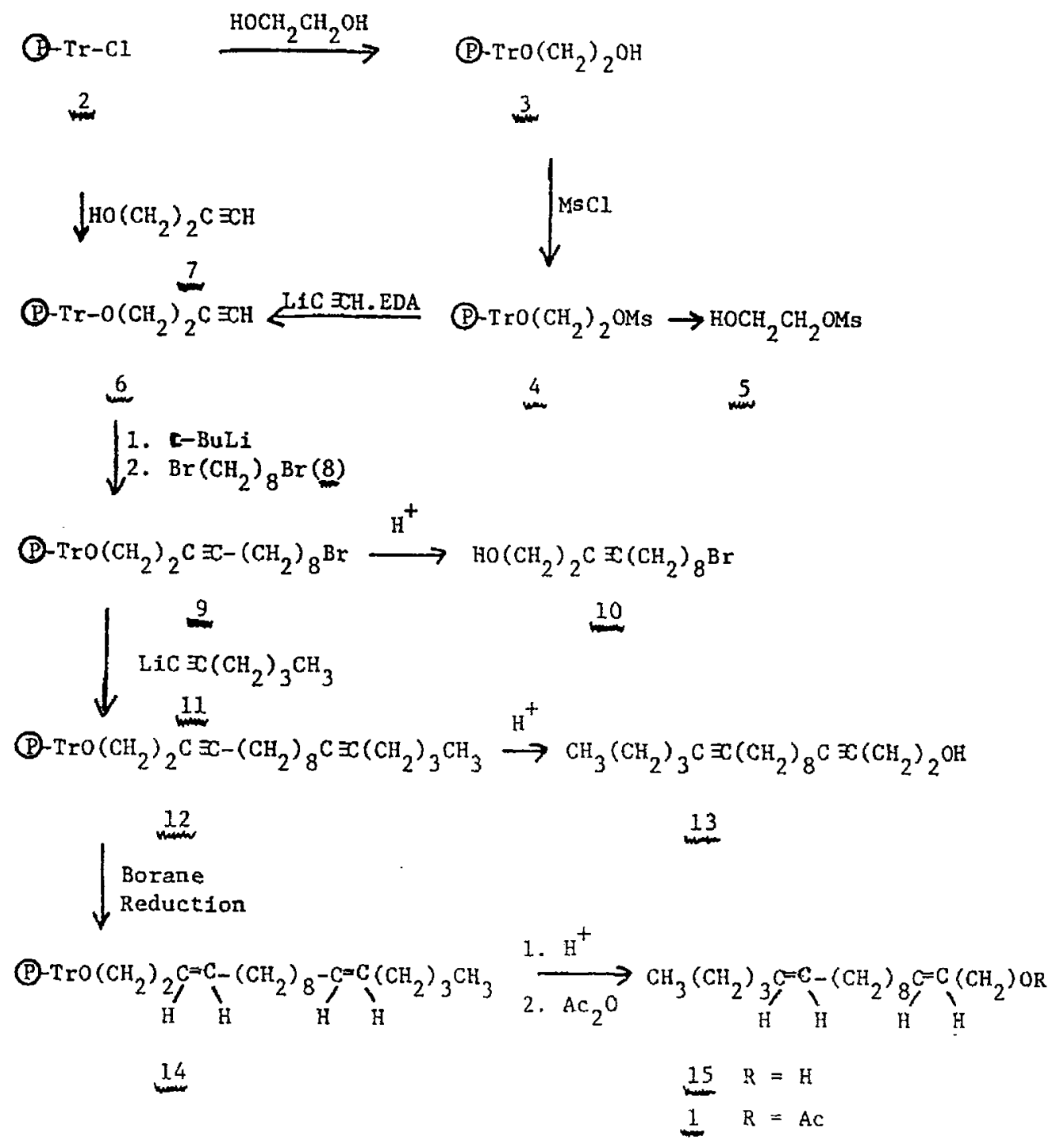

FIG. 1 .

The seven step synthesis of 1 on insoluble polymer supports in an overall yield of $30 \%$ represents a synthesis long enough to set up for the automated procedures possible in solid-phase methodology. In addition, the use of the solid phase to monoprotect 1,2-ethanediol to form 3, to monoreact with 1,8-dibromooctane (8), and to facilitate the work-up of the borane reduction step leading to $\mathbf{1 4}$ (hydrogen peroxide does not have to be used to make borane impurities water soluble) illustrates some of the advantages of solidphase synthesis of diolefinic pheromones.

As a control to the solid phase synthesis of 1 , we prepared 1 by solution methods related to, but not identical with, those previously described (Doolittle et al., 1980; Uchida et al., 1978) and to our solid-phase method 
described above. Treatment of the lithium salt of the tetrahydropyranyl ether of 3-butyn-1-ol (16) with a large excess of the symmetrical 1,8-dibromooctane (8) in THF-HMPT gave the tetrahydropyranyl ether of 12-bromo-3-dodecyn1-ol (17) in only $23 \%$ yield accompanied by many by-products, despite the fact that a similar sequence of reactions gave a monobromoalkyne in high yield from a symmetrical dibromo compound using the dihalide in excess (Burgstahler et al., 1977). This similar reaction was accomplished on solid phases in 54\% yield with the additional advantage that the product was purified by simple filtration, the by-products and excess dihalide remaining in the filtrate. In a second synthetic approach to 1 in solution, 1,8-octanediol (18) was converted to 8-chloro-1-octanol (19) and hence to 8-chloro-1-octanol tetrahydropyranyl ether (20). Coupling of 20 with 1-lithio-1-hexyne (11), as before, yielded the tetrahydropyranyl ether of 9-tetradecyn-1-ol (21). Acid hydrolysis of 21 gave 9-tetradecyn-1-ol (22) in $84 \%$ yield from 20 as shown in Figure 2. Conversion of 22 into 1-bromo-9-tetradecyne (23) with bromine and triphenylphosphine in pyridine (Disselnkotter et al., 1976) was achieved in $84 \%$ yield. This proced ure represents an improvement over previous methods (Doolittle, 1980; Uchida, 1978). Coupling of 23 with 16, as before, followed by acid hydrolysis, gave 3,13-octadecadiyn-1-ol (13) in $85 \%$ yield. Reduction of 13 with dicyclohexylborane or disiamylborane, as above, yielded $(Z, Z)-3,13$ octadecadien-1-ol (15) in 85\% yield. Acetylation of 15 yielded 1 in nearly quantitative yield.

$$
\begin{aligned}
& \mathrm{X}\left(\mathrm{CH}_{2}\right)_{8} \mathrm{Y} \\
& \stackrel{11}{\longrightarrow} \mathrm{ThpO}\left(\mathrm{CH}_{2}\right)_{8} \mathrm{C} \equiv \mathrm{C}\left(\mathrm{CH}_{2}\right)_{3} \mathrm{CH}_{3} \\
& 18 \mathrm{X}=\mathrm{Y}=\mathrm{OH} \\
& 19 \mathrm{X}=\mathrm{OH}, \mathrm{Y}=\mathrm{C} 1 \\
& 20 \mathrm{X}=\text { OThp, } \mathrm{Y}=\mathrm{Cl} \\
& \stackrel{\mathrm{H}^{+}}{\longrightarrow} \mathrm{HO}\left(\mathrm{CH}_{2}\right)_{8} \mathrm{C} \equiv \mathrm{C}\left(\mathrm{CH}_{2}\right)_{3} \mathrm{CH}_{3} \stackrel{\mathrm{Br}_{2}, \mathrm{Ph}_{3} \mathrm{P}}{\longrightarrow}
\end{aligned}
$$

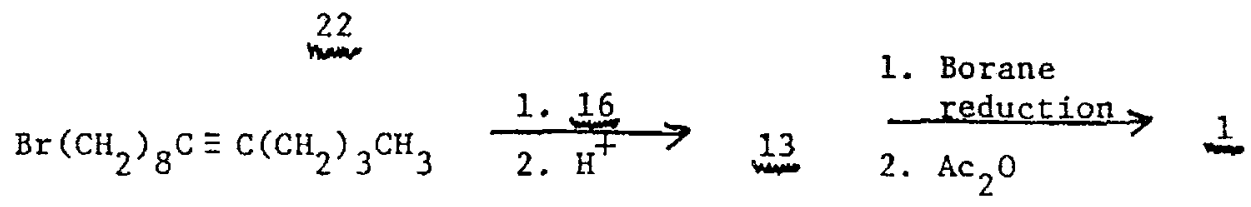

Fig. 2. 
The almost identical approach to the synthesis of 15 on polymer supports and in solution via the symmetrical 8 favors the solid-phase approach. The much better solution-phase synthesis of 1 (Figure 2) went in 32\% yield based on the symmetrical 18 and 16 in eight steps. The polymer-based synthesis gave 15 in $30 \%$ overall yield from 8 and 16 in only five steps, or from 8 and the more simple 1,2-ethanediol in seven steps with the advantages outlined before. The main disadvantage of polymer-based synthesis arises from the fact that the solid-phase syntheses work more efficiently using polymers containing only $10-25 \%$ of the phenyl groups of 2 functionalized and hence reaction volumes tend to be five to ten times larger than comparable reactions in solution. One long standing problem in organic synthesis on polymer supports has been recently alleviated using $\left[{ }^{13} \mathrm{C}\right] N M R$ spectroscopy (Jones et al., 1982). In fact, we have recently characterized polymer-bound trityl alcohol $(2, \mathrm{Cl}=\mathrm{OH}), 3$, 4,6 , and 9 by this method. Cleavage of a polymer-bound substrate from the polymer still remains the major quantitative method of evaluating the yield of each reaction step.

The solid-phase synthesis of $(Z, Z)-7,11$-hexadecadien-1-yl acetate (24), a sex pheromone component of the pink bollworm moth, Pectinophora gossypiella, has been reported by many synthetic routes (Henrick, 1977; Rossi, 1977; Disselnkötter, 1976; Su, 1974; Sonnet, 1979; Mori, 1975; Anderson, 1975) in solution. In the same retrosynthetic analysis of 24 as that described above for 1 , the symmetrical synthon in the middle of the molecule is simply 1,2-dibromoethane (25). We felt, however, that the coupling of an acetylene to 25 would give a $\beta$-bromoacetylenic intermediate, which on subsequent reaction would lead to elimination instead of coupling. This prediction was in fact borne out, as shown in Figure 3.

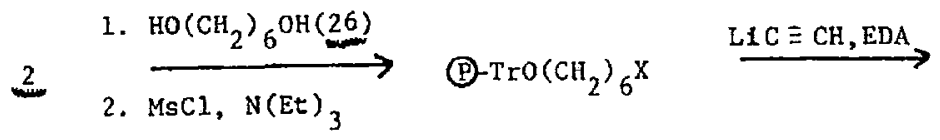

$$
\begin{aligned}
& 27 \quad \mathrm{X}=\mathrm{OH} \\
& 28 \mathrm{X}=\mathrm{OMs} \\
& \text { (D- }-\operatorname{rrO}\left(\mathrm{CH}_{2}\right)_{6} \mathrm{C} \equiv \mathrm{CH} \\
& \text { 1. } n-B u L i \\
& \text { 2. } \mathrm{CH}_{3}\left(\mathrm{CH}_{2}\right)_{3} \mathrm{C} \equiv \mathrm{CCH}_{2} \mathrm{CH}_{2} \mathrm{X} \\
& \text { 30. } \quad \mathrm{CH}_{3}\left(\mathrm{CH}_{2}\right)_{3} \mathrm{C} \equiv \mathrm{CCH}=\mathrm{CH}_{2} \\
& 30 \\
& \text { (32) } \quad x=214 \\
& \text { (32a) } \quad x=B T
\end{aligned}
$$

FIG. 3. 


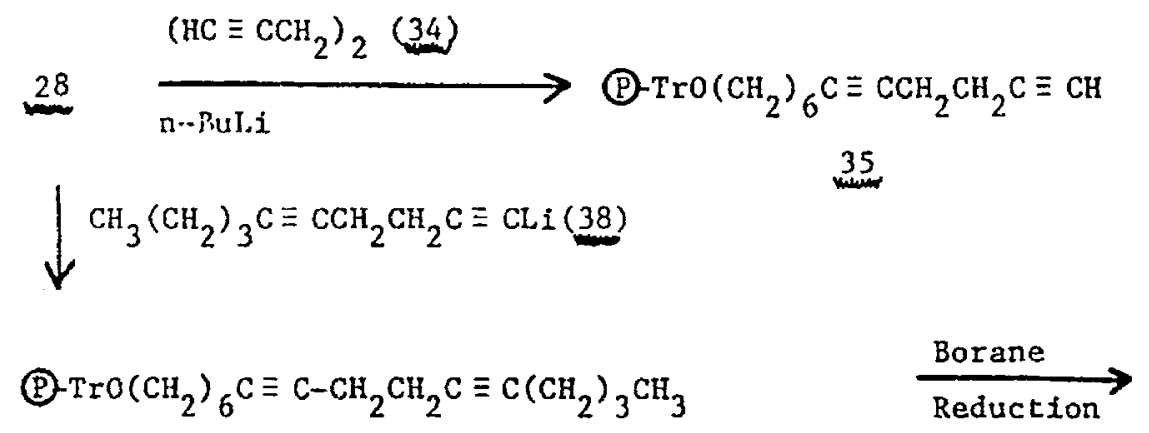

$$
\begin{aligned}
& 37 \\
& \text { (P- } \mathrm{TrO}\left(\mathrm{CH}_{2}\right)_{6}^{\mathrm{C}=\mathrm{C}} \underset{\mathrm{H}}{\mathrm{C}}-\mathrm{CH}_{2}{ }_{\mathrm{H}}^{\mathrm{CH}} \underbrace{\mathrm{C}=}_{\mathrm{H}} \mathrm{C}-\left(\mathrm{CH}_{2}\right) \mathrm{C}_{3} \mathrm{CH}_{3} \\
& \underset{\text { 2. } \mathrm{H}^{+}}{\stackrel{\mathrm{Ac}_{2} \mathrm{O}, \mathrm{py}}{\longrightarrow}} \\
& 40 \\
& \mathrm{CH}_{3}\left(\mathrm{CH}_{2}\right)_{3}{ }_{\mathrm{H}}^{\mathrm{C}=\mathrm{CCH}_{2}} \mathrm{CH}_{\mathrm{H}} \mathrm{CH}_{\mathrm{H}} \mathrm{C=}=\overbrace{\mathrm{H}}\left(\mathrm{CH}_{2}\right)_{6} \mathrm{OR} \\
& 41 \quad \mathrm{R}=\mathrm{H} \\
& 24 \quad R=A C
\end{aligned}
$$

1. $n-B u L i$

2. $\mathrm{BuBr}$

Fig. 4.

Thus polymer 2 reacted with 1,6-hexanediol (26) at one end only to give the polymer-bound monotrityl ether of 1,6-hexanediol (27) (Svirskaya et al., 1979; Fréchet, 1981) which was mesylated, as for 4, to give the polymer-bound monotrityl ether of 1,6-hexanediol monomesylate (28) (Leznoff et al., 1977). Acid cleavage of 28 liberated $0.62 \mathrm{mmol}$ of 1,6-hexanediol monomesylate (29). Treatment of 28 with the lithium acetylide complex, as before, gave the polymer-bound monotrityl ether of 7-octyn-1-ol (30). Acid cleavage of 30 gave 7-octyn-1-ol (31) (Ames and Goodburn, 1967) in 50\% yield based on 28. When 30 reacted with $t$-BuLi and 3-octyn-1-yl mesylate (32), only 30 was recovered. In a model reaction, 1-bromo-3-octyne (32a) (Disselnkötter et al., 1976) reacted with $n$-BuLi to give the known elimination product 1-octen-3yne (33) (Anzilotti and Vogt, 1939). Thus, 1,2-dibromoethane would not be a suitable symmetrical intermediate for the synthesis of 1,4-diynes. Another symmetrical synthon derived from 24 can be envisioned, namely, 1,5- 
hexadiyne (34). Thus, treatment of 28 with the lithium salt of 34 led to the polymer-bound trityl ether of 7,11-dodecadiyn-1-ol (35). Acid cleavage of 35 gave 7,11-dodecadiyn-1-ol (36) in $27 \%$ yield based on 28 . Subsequent coupling of 35 with $n$-BuLi and butyl bromide gave polymer-bound trityl ether of 7,11-hexadecadiyn-1-ol (37). Alternatively 37 was prepared by direct coupling of 28 with $n$-BuLi and 1,5-decadiyne (38). Acid cleavage of 37 liberated $0.21 \mathrm{mmol}$ of 7,11-hexadecadiyn-1-ol (39) per g showing that 37 was formed in $37 \%$ yield using 38 but in only $20 \%$ yield using 34 . Borane reduction of 37 via 38, as before, gave the polymer-bound trityl ether of $(Z, Z)-7,11$ hexadecadien-1-ol (40). Acid cleavage of 40 afforded $(Z, Z)$-7,11-hexadecadien-1-ol (41) in $67 \%$ yield based on polymer 37. Acetylation of 41 gave the desired pheromone 24 in high yield (Figure 4).

The overall yields of 24 synthesized via 38 on solid phases, as shown in Figure 4, are similar to the yields obtained by similar solution methods. The advantages and disadvantages of solid-phase synthesis were similar to those described above for the synthesis of 1, except that for 1,4-diynes, one cannot use the inexpensive symmetrical dihalide. Unfortunately the symmetrical synthon 34 gives low yields, probably due to allenic impurities (Mori et al., 1975). Analysis of 1 and 24 by high-pressure liquid chromatography (HPLC) showed that all the products exhibited not less than $90 \%$ and more commonly 93-98\% of the cis, cis isomer. The stereochemical purity of 1 was identical when 1 was synthesized by solid phase or solution methods.

The syntheses of 1 and 24 demonstrate a practical synthesis of unconjugated diolefinic pheromones using solid-phase methodology. Furthermore, one can see that unconjugated tri-, tetra-, and oligoacetylenic compounds can be prepared by the repetitive additions of symmetrical difunctionalized synthons to a growing polymer-bound hydrocarbon chain.

Acknowledgments - We thank the Natural Sciences and Engineering Research Council of Canada for a strategic grant in aid of this research.

\section{REFERENCES}

Alvarado-Urbina, G., Sathe, G.M., Liu, W.C., Cillen, M.F., Duck, P.D., Bender, R., and OGILviE, K.K. 198I. Automated synthesis of gene fragments. Science 214:270-274.

A.mes, D.E., and Goodburn, T.G. 1967. Synthesis of long-chain acid. Part VIII. 9,10,18Trihydroxyoctadecanoic Acid. J. Chem. Soc. (C) 1556-1558.

Anderson, R.J., and Henrick, C.A. 1975. Stereochemical control in Wittig olefin synthesis. Preparation of the pink bollworm sex pheromone mixture, gossyplure. J. Am. Chem. Soc. 97:4327-4333.

ANZILOTII, W.F., and VoGt, R.R. 1939. The preparation of $\alpha$-Alkyl- $\beta$-alkenylacetylenes. J. Am. Chem. Soc. 61:572-573.

Brown, H.C., and ZweIFEL, G. 1961. Hydroboration XI. The hyroboration of acetylenes-a convenient conversion of internal acetylenes into cis-olefins and the terminal acetylenes into aldehydes. J. Am. Chem. Soc. 83:3834-3840. 
Blrgstahler, A.W., Weigel, L.O., Sanders, M.E., Shaefer, C.G., Bell, W.J., and Vuturo, S.B. 1977. Synthesis and activity of 29-hydroxy-3,11-dimethyl-2-nonacosanone, Component $B$ of the german cockroach sex pheromones. J. Org. Chem. 42:566-568.

Disselnkörter, H., Eiter, K., Kare, W., and Wendish, W. 1976. Trennung und analytische Bestimmung synthetischer Pheromone am Beispiel der isomeren 7,11-Hexadecadien-1ylacetate (Gossyplure) Tetrahedron 32:1591-1595.

Doolittle, R.E., Proveaux, A.T., and Heath, R.R. 1980. Synthesis of sex pheromones of lesser peachtree borer. J. Chem. Ecol. 6(1):271-83.

EbATA, T., and MORI, K. 1979. A convenient synthesis of a mixture of $(Z, Z)-3$, 13-octadecadienyl acetate and its $(E, Z)$ isomer, the attractant for the cherrytree borer. Agric. Biol. Chem. 43:1567-1570.

ERICKson, B.W., and MerRifield, R.B. 1976, pp. 255-527. In H. Neurath and R.L. Hill (eds.). The Proteins. 3rd ed., Vol. II, Academic Press, New York.

FRÉCHET, J.M.J. 1981. Synthesis and applications of organic polymers as supports and protecting groups. Tetrahedron 37:663-683.

FRÉCHET, J.M.J., and NLYENS, L.J. 1976. Use of polymers as protecting groups in organic synthesis. III. Selective functionalization of polyhydroxyalcohols. Can. J. Chem. 54: 926-934.

FyLes, T.M., and LeZNOFF, C.C. 1976. The use of polymer supports in organic synthesis. V. The preparation of monoacetates of symmetrical diols. Can. J. Chem. 54:935-942.

FyLES, T.M., LeZNOFF, C.C., and WeATHERSTON, J. 1977. The use of polymer supports in organic synthesis. XII. The total stereoselective synthesis of cis insect sex attractants on solid phases. Can. J. Chem. 55:4135-4143.

HENRICK, C.A. 1977. The synthesis of insect sex pheromones. Tetrahedron 33:1845-1889.

Jones, A.J., Leznoff, C.C., and Svirskaya, P.I. 1982. Characterization of organic substrates bound to crosslinked polystyrenes by ${ }^{13} \mathrm{C}$ NMR spectroscopy. Org. Magn. Reson. 18:236-240.

LeZNoFf, C.C., Fyles, T.M., and WeATHERston, J. 1977. The use of polymer supports in organic synthesis. VIII. Solid phase syntheses of insect sex attractants. Can. J. Chem. 55:1143-1153.

LEZNOFF, C.C. 1978. The use of insoluble polymer supports in general organic synthesis. Acc. Chem. Res. 11:327-333.

Mori, K., Tominaga, M., and Matsui, M. 1975. Stereoselective synthesis of the pink bollworm sex pheromone, $(Z, Z)-7,11$-hexadecadienyl acetate and its $(Z, Z)$ isomer. Tetrahedron 31:1846-1848.

Rossi, R., 1977. Insect pheromones; 1 Synthesis of achiral components of insect pheromones. Symthesis 13:817-836.

SCHWARTZ, M., and Waters, R.M. 1972. Insect sex attractants; XII. An efficient procedure for the preparation of unsaturated alcohols and acetates. Synthesis 8:567-568.

STILL, C.W., KAHN, M., and MITRA, A. 1978. Rapid chromatographic technique for preparative separations with moderate resolution. J. Org. Chem. 43(14):2923-2925.

SU, H.C.F., and MAHANY, G. 1974. Synthesis of the sex pheromone of the female Angoumois grain moth and its geometric isomers. J. Econ. Entomol. 67:319.

Svirskaya, P.I., Leznoff, C.C., Weatherston, J., and Laing, J.E. 1979. Synthesis of transalken-1-ols as candidates for insect sex attractants. J. Chem. Eng. Data 24:152-155.

Svirskaya, P., Leznoff, C.C., and Roelofs, W.L. 1980. A steroselective synthesis of a cis, cis conjugated dienol, a candidate pheromone. Synth. Commun. 10(5):391-397.

UChidA, M., Mori, K., and Matsui, M. 1978. Synthesis of $(Z, Z)-3$, 13-octadecadienylacetate and its $(E, Z)$ isomer, the attractant for the cherrytree borer. Agric. Biol. Chem. 42(5): 1067-1070.

Zweifel, G., and Polston, N.L. 1970. Selective hydroboration of conjugated diynes with dialkylborane. A convenient route to conjugated cis-enynes $\alpha, \beta$-acetylenic ketones, and cis, cis-dienes. J. Am. Chem. Soc. 92:4068-4071. 